\title{
Marine Parasites as an Object and as a Factor in the Problem of Invasive Species in Marine Ecosystems: Reflections on the Topic
}

\author{
Machkevskyi Volodymyr $\mathrm{K}^{1^{*}}$, Sarah Al-Jufaili ${ }^{1}$, Ridah Khalfan $^{1}$ and Nashwa AM Al-Mazrooei ${ }^{1}$ \\ ${ }^{1}$ Fishery Quality Control Center of Ministry of Agriculture \& Fisheries Wealth of Sultanate of Oman
}

*Corresponding author: Machkevskyi Volodymyr K, Professor, Fishery Quality Control Center of Ministry of Agriculture \& Fisheries Wealth of Sultanate of Oman, Tel: +96895273089; E-mail: vladmachkevsky@gmail.com

Received date: Mar 19, 2015; Accepted date: June 04, 2015; Published date: June 11, 2015

Copyright: $\odot 2015$, Volodymyr MK. This is an open-access article distributed under the terms of the Creative Commons Attribution License, which permits unrestricted use, distribution, and reproduction in any medium, provided the original author and source are credited.

\begin{abstract}
The distribution of organisms in space is a natural function which ensures the spreading of genes and establishment of populations. The insertion of a new species into ecosystems is a process that has been occurring for centuries, and in many cases, is influenced by human interference, whom knowingly or unknowingly aids in spreading different species around the world. Marine parasites, in particular, can act as Invasive Species (IS) and also as environmental factors affecting the free living IS in the Recipient Ecosystem (RE). For Parasite Invaders (PI), there exists mechanisms that prevent its invasion in RE. The mechanisms of elimination of PI are very diverse, from grazing of parasites' free-living stages by hydrobionts to the defense reactions of native organisms which $\mathrm{PI}$ will use as hosts. There are two possibilities to a successful introduction of PI. The first is the "soft" introduction of PI into the system interconnections of RE. The second variant can develop on the dysfunctional scenario for the recipient ecosystem. The result of the introduction depends on the individual characteristics of the PI. Marine parasites can be controlling factors which prohibit or prevent the establishment of free living IS at the invasion area. As a basis for logical constructions, we used the conception of Parasite Systems as normal component of ecosystems.
\end{abstract}

\section{Introduction}

All existing organisms in the Biosphere of the planet Earth have a constantly decide threefold task; to preserve their species, its reproduction and distribution. Throughout the history of life on Earth living organisms develop new areas for its existence. These processes have lasted for centuries and are preserved to this day. However, over the last 5 to 7 decades the distribution of organisms mediated by highspeed craft and industrial activity. The scale of the impact of activities such as sea transportation and aquaculture on marine ecosystems in the introduction of invasive species, are huge and difficult to assess and to control [1].

The question is, can invasive species be considered good or bad to the ecosystems? From the standpoint of maintaining of ecosystem stability the invasive species can be the beginning of a violation of its stability (homeostasis), i.e. start of ecosystems succession. However, to assess the implications of such a phenomenon requires long time observation and assessment. Invasive species in the new environment will be exposed to aggression by indigenous aquatic organisms and they themselves begin to actively influence the biocenosis in order to find a suitable ecological niche. This equally applies to the parasites, which are known to display amazing ability to survive, reproduce and disseminate in environment.

Here we will consider the parasites as invasive species that cause and aggressive reaction to the environment. We would like to consider parasites as invasive species and parasites as aggressive factor in relation to the free-living invasive species.

\section{About parasites}

Parasitism as a form of existence of living matter arose almost simultaneously with the free-living forms of life and parasites achieved outstanding biological diversity, firmly established in the Biosphere [2]. A characteristic feature of parasitic organisms is that they use another organism (plant, animal, another parasite), referred to as the host. By their nature, parasites are antagonists of their hosts, because they consume resources and produce products of metabolism and pressure the metabolic system of their owners. However, it is noteworthy that parasites don't benefit from exhausting or killing their owners. Because this will lead to loss of habitat to these parasites which is a threat to their existence. Therefore in the process of coevolution, parasites "learned" to reduce their harm on their hosts to the minimum and in return their host "learned" to evade the aggressive impact of these parasites. Therefore, in most cases, parasites and hosts coexist in relatively peaceful dynamics.

\section{About parasitic system}

Co-evolution has led to different types of parasites and together with their hosts they were united in the so-called Parasitic Systems (PS) [3]. PS can be defined as parasite centric formation, the core of which is the population (species) of the parasite, including all parasitic stages of its life cycle. Organisms that ensure the existence of all life stages of the parasite are external (free-living) components of the PS. Depending on the type of the parasite's life cycle, PS can be divided into bicomponent PS (binomial) and multicomponent (three, four, five). Also, depending on the degree of specificity of the parasite to their hosts, i.e. the number of host species which can be used by parasite for the implementation of its life cycle, the PS can be simple or complex.

By means of PS parasites carry out a number of important functions in ecosystems: a complication of their structure, redirecting pathways of matter and energy (Figure 1), the selection of the most viable genotypes hosts and control of invasive species, which ultimately 
Citation: Volodymyr KM, Al-Jufaili S, Khalfan R, Al-Mazrooei NAM (2015) Marine Parasites as an Object and as a Factor in the Problem of Invasive Species in Marine Ecosystems: Reflections on the Topic. J Biodivers Endanger Species 3: 154. doi: $10.4172 / 2332-2543.10 .4172 / 2332-2543.1000154$

Page 2 of 5

ensures the sustainability of ecosystems [4]. Whenever we consider the problem of resettlement of parasites, we must understand that we are talking about the creation of the new conditions of new PS. And whenever we are faced with free-living species of invasive species, we should understand that native parasites will try to integrate them into their PS, testing the strength of their defensive reactions.

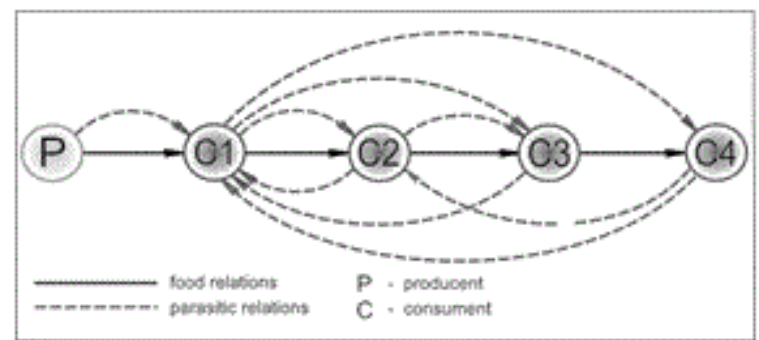

Figure 1: Scheme of the parasites role in the trophic chain of the marine ecosystem.

\section{Parasites as invasive species}

To understand the mechanisms and migration routes of invasive parasites, we primarily make a brief excursion into the life cycle, and hence the structure of parasitic systems (Figure 2). During the phylogeny of each large taxonomic group of parasites there was generated a certain type of life cycle, respectively of it model of PS. Bicomponent PS are characteristic of many species of flagellates, microsporidia, myxosporeans, parasitic turbellarians, monogenic, some parasitic nematodes, parasitic copepods and parasitic isopods. Low specificity monogenean parasites exhibit bicomponent parasitic systems (BPS) which are complicated in many cases (Figure 2). In the case of high specificity to its hosts they usually follow simple BPS (Figure 2), these are less common. In the life cycle of these parasites, there is only one host and only one dispersed stage (spore, egg, larva), whereby there is an infection of new host species. Multicomponent PS is composed of systems containing more than two parasitic stages. This type of system is typical for what are known as phase parasites [3], which have several stages (phases) of the life cycle (Figure 2). These parasites include primarily trematodes that have parthenogenetic and androgynous lifecycle phases. Each of these phases has its own host type and characteristic dispersed larva, miracidia and cercariae, respectively. During the evolution trematodes got additional host in which parasites metacercariae - the next stage after cercariae. Thus, the vast majority of trematodes forms a fourcomponent PS. Which as in the above example can be simple (rarely) or complex (majority) (Figure 2). Similarly trematodes with small differences share taxonomically specific multicomponent PS with Aspidogastrea, Cestoda, Acanthocephala and many species of Nematoda. Relatively recently it has been demonstrated that some of the Myxozoan parasites have three component PS. Based on the specificity of the structure of parasite systems we can construct a theoretical model of infestations into new ecosystems. The likely success of resettlement of the primarily parasites it can be expected from the two-component systems parasitic because they only need one host. Moreover, the more likely the success of the parasites of the complicated BPS, as they have a predisposition to a broader ecological and physiological parameters of the new hosts. These parasites can be from Myxozoa, Microsporidia, Monogenea, Nematoda, parasitic
Copepoda and parasitic Isopoda. The situation is different in parasites that form multi-component PS. On the one hand, these parasites are more demanding in terms of the environment habitat and the availability of suitable hosts. On the other hand, they are genetically fixed to be highly adaptive in terms on their activity, suiting a wider range of hosts which allows them a successful of the invasion and ability to secure in a new environment. Understanding the structure of the implementation of its parasitic life cycles by PS is the basis for understanding the mechanisms of parasite invasion into new regions.

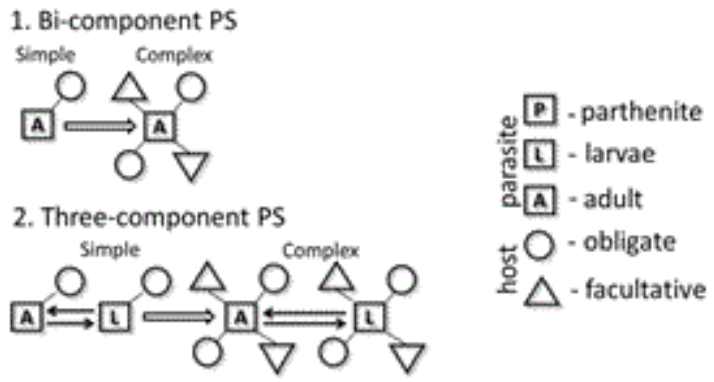

3. Four-component PS

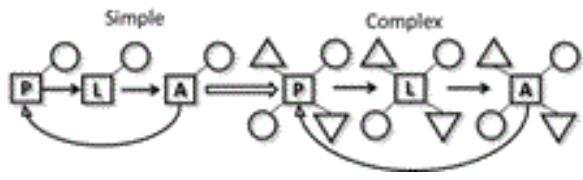

Figure 2: Scheme of Parasitic System: a - bi-component; b - threecomponent; $\mathrm{c}$ - four -component (simple and complex).

\section{Mechanism of the invasion}

We have considered several possible options for movement of marine parasites into new regions.

First way could be achieved through the transfer of parasites from the bottoms of ships by aquatic fouling community (epibionts), which with varying length exists on the bottoms of ships between docks or diving immersion cleaning of the ships. Communities of epibionts are primarily formed of bryozoans, bivalves, barnacles, etc. once they settle they find shelter and food and are followed by the appearance of other organisms such as molluscs, polychaete worms, various crustaceans and even small fish (Blennidae, Gobiidae, Labridae) which are characterized by having a sedentary life. Experience shows that such "wandering ship community" (WSC) as units may be functional for months or even years, crossing the expanse of water in all directions. What are the chances on transfer it gives to parasites? Parasites can be embedded in the "WSC" by dispersed stages. Some of them infect the aquatic life of "WSC" and (or) are kept till a suitable habitat if found in another port. It should be noted that the life expectancy of dispersed stages of parasites in the environment while preserving the ability to invade the host varies from several hours up to several days (parasitic Turbellaria, Trematoda, Monogenea), months (eggs of Trematoda, Monogenea, Nematoda, parasitic Crustacea larvae) or several years (Mixozoa, Microsporidia) [5]. From it largely depends on the success of resettlement of the parasite into a new area.

For example, eggs laid by monogeneans (BPS), which have very good device for attachment to a solid substrate (Figure 3 ) are anchored among biofoulings. They will have a chance to infect fish from "WSC" 
Citation: Volodymyr KM, Al-Jufaili S, Khalfan R, Al-Mazrooei NAM (2015) Marine Parasites as an Object and as a Factor in the Problem of Invasive Species in Marine Ecosystems: Reflections on the Topic. J Biodivers Endanger Species 3: 154. doi: $10.4172 / 2332-2543.10 .4172 / 2332-2543.1000154$

Page 3 of 5

or 2-3 weeks to infect other species of fish in the port of destination at a distance of thousands of miles. This postulate illustrates the case (without ships), which took place in the lagoons of Sardinia, where monogeneans Sciaenicotyle pancery, parasitic on wild Umbrina cirrosa fish, coming for gratuitous feed cages that were likely infected eggs networks. The dispersed larvae of S. pancery, infected cultured croakers Argirosomus regius [6], resulting in the development of a massive epizootic disease and led to the mortality of a significant number of the cultured fish. On a similar scenario we can develop the resettlement of any monogeneans, which attach their eggs among biofoulings on the bottoms of ships. However, the introduction of parasites in the new areas and the success of infestation of the new hosts will depend on many factors and is not always guaranteed to be successful for the invasive species. One of these factors is critical number of invasive stages which reached a new region and can establish a new parasite system there.

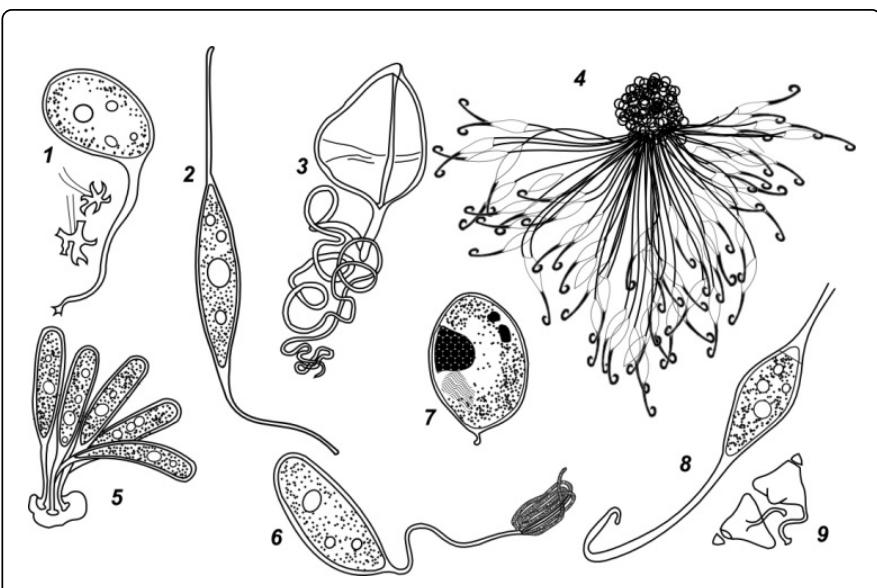

Figure 3: Eggs of selected species of Monogenea with different devices for attach to substrate.

Second way is through the spreading through the biofouling community which is a good chance for parasites who are forming BPS and MPS. In places of more or less continuous berthing of vehicles to their bottoms many schools of demersal fish come searching for a food resource, each of which has its ecto-and endo- parasite fauna and from which every adult parasite almost without interruption is in a state of reproduction. As a result of this contact between itenerant free-living aquatic animals and local PS-s the first will be infected by indigenous parasites. Molluscs with gregarine, microsporidians, parthenites and metacercariae of trematodes, cestode and nematode larvae; polychaete will be infected with myxozoans, metacercariae of trematode, larvae of nematodes; crustaceans will harbor gregarines, microsporidians, metacercariae of trematode, larvae of cestodes and nematodes. And lastly, Fish will be infected with myxozoans and microsporidians, adults and larval forms of different helminthes. As an example and according to research based observations in the Black Sea, the host of parthenogenetic phase of trematode Proctoeces maculatus is the Mediterranean mussel Mytilus galloprovincialis. Labridae fish infected mussels during the settlement of a fishing vessel during, which resulted in transportation of the parasites infective stages to other regions, giving a chance for $P$. maculatus partenitae infrapopulation to spread their PS to other areas. Apparently, so there was migration of $P$. maculatus from the Mediterranean basin, where it is widespread $[7,8]$ to the coast of South Africa. First M. galloprovincialis with the ships, then they started reproducing on the bottoms of ships and adult mussels created the necessary pool of larvae, which led to the establishing of the population of $M$. galloprovincialis in the new area. Migration of $P$. maculatus likely happened to the example described above. This trematode, having a broad specificity to the definitive and second intermediate hosts [9] has quite easily formed multicomponent PS by local hydrocoles and spread along the coast of South Africa. As a second intermediate host P. maculatus found indigenous mussel Perna perna, which metacercariae infestation reached 62\% [10].

Third way to spread the parasites is through ships that berth at the quay wall that is covered with local communities of epibiont. In its "WSC " on the bottom certainly fish like Blennidae and Gobiidae) will be attracted and be infected with adults parasites that were able to survive in such communities. But the number of mature parasites reached the introduced range to exceed a critical minimum needed to create the "old" PS with new hosts. It takes time, and in each case is different. For example, one of the possible ways of settling round goby Apollonia melanostoma the Baltic Sea and the Great Lakes from the Ponto-Caspian basin was through community of ship epibionts[11]. This species in native habitat is infected with 72 species of parasites, including myxosporeans, monogeneans, trematodes, cestodes, acanthocephalans, nematodes, parasitic copepods. However, in the introduced range over 10 years, A. melanostoma accustomed 16 parasite species mainly of but larval forms[12], suggesting that it had received them in introduced range. Round goby is embedded in local PS, but none of its native parasites has formed the PS in a new region or didn't reach numbers that allows to detect them. Probably ten years is too short for this process. Subsequent observations will show whether this is so? Fourth way. Ballast water is a powerful tool for the transfer of marine aquatic organisms, including parasites. The success of resettlement parasites through ballast water will largely depend on several factors. The survival of their dispersed stages or survival of the parasite infected host. It is known that in ballast water on any given day, vessels that travel the ocean transport over 3000 species of parasites[13]. Probably, there may also contain spores of gregarine, myxosporeans, microsporidia, helminth eggs. But the likelihood of achieving their suitable habitats and hosts and the subsequent formation of population with the dispersed stages is lower that the critical minimum for the formation of PS due to the low probability of survival in the ballast water of infected hosts and parasites of introduced biological communities in a critical minimum number of them.

Fifth Way. Furthermore, the deliberate introduction of species of fish and shellfish with poor sanitary control broodstock is another way of introduction of invasive species into marine ecosystems. With them in the new ecosystem can be stored are not typical for it parasites. Since copepods Mytilicola orientalis, M. intestinalis, Myicola ostrae, parasitic in bivalves have been successfully introduced into new areas through the activities of farmers engaging in the cultivation of oysters and mussels. Also well-known such cases of transfer of fish parasites the monogeneans Gyrodacylus salaris, G. anguilla, Pseudodactylogirus anguillae, P. bini, Neobenedenia melleni, nematode Anguillicola crassus and others [14]. In such cases, in the new habitats often attacks the alien parasites that are exposed not only to the populations of cultured aquatic organisms, but also to the wild stocks.

In each of the above five pathways of parasites are two versions of events. First New parasite faces a number of external obstacles that hamper the development of its population such as the negative reaction of new hosts or adverse environmental biotic and abiotic factors. Consequently, the parasite introduced "soft" is built into the 
Citation: Volodymyr KM, Al-Jufaili S, Khalfan R, Al-Mazrooei NAM (2015) Marine Parasites as an Object and as a Factor in the Problem of Invasive Species in Marine Ecosystems: Reflections on the Topic. J Biodivers Endanger Species 3: 154. doi: $10.4172 / 2332-2543.10 .4172 / 2332-2543.1000154$

Page 4 of 5

new ecosystem, as was the case with Ligophorus kaohsianghsieni[15] These monogeneans moved into the Black Sea ecosystem with the artificially introduced haarder mullet Mugil soiuy from the Far East. During the 20 year period, the introduced monogeneans $\mathrm{L}$. kaohsianghsieni in its parasitic system included indigenous golden mullet Liza auratus. The second option involves the dramatic developments. New parasite faces no obstacles for the development of its population and is rapidly increasing in numbers and creates a problem in the new ecosystem in the form of an epizootic. Became a textbook example of monogeneans Nitzschia sturionis, which was introduced accidentally into the Aral Sea with acclimatized Volga Stellate Sturgeon Acipenser stellatus. Relatively harmless in places such as the Black, Azov and Caspian Seas, this parasite which was passed to the Aral Ship Acipenser nudiventris (Figure 4) turned into a nightmare to the Aral Sea. Population of Aral Ship was an endemic of Aral Sea. Ship in the Aral Sea had enough representative natural parasite fauna including 21 species: trematodes ( 66,6-80,6 \%), parasitic crustaceans ( 50,0-77,4 \%), monogeneans ( $64,5-75,0 \%)$, nematodes ( 57,8-58,3 \%), cestodes (3,2-8,3\%)[16]. However introduction in its parasite fauna the new monogenean $N$. sturionis led to the catastrophe of the Aral population of A. nudiventris. Many centuries ago it has evolved separately from other sturgeons, which its ancestors had lived in Ocean Thetis, united together in ancient times to the current Mediterranean, Black, Azov, Caspian and Aral Seas. This species was not physiologically ready to meet the new parasite and proved vulnerable to it. Occurrence of $N$. sturionis in the Aral Sea is more than 5 times increased compared with the Caspian one (Figure 4). N. sturionis proved highly pathogenic for Aral Ship causing an epizootic which killed off the whole population of the A. nudiventris. Aral Ship the time of acclimatization of Volga Stellate Sturgeon and first registration in the Aral Sea was the most numerous of the four Sturgeons species in the native fish fauna of the Aral Sea. By 1995, the A. nudiventris in Aral Sea disappeared completely [17].

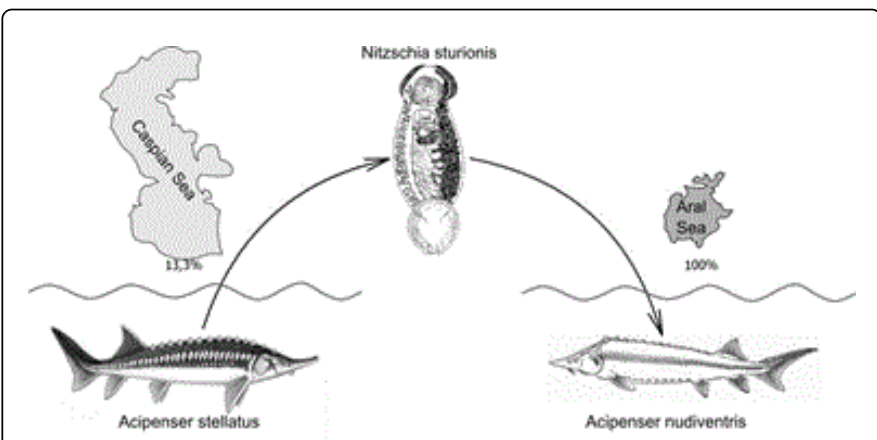

Figure 4: Scheme of introduction of monogenean Nitzschia sturionis from the Caspian Sea Ecosystem to the Aral Sea Ecosystem.

\section{Parasites as a controlling factor}

Anyway free-living aquatic hydrobionts in new conditions and are (or do not appear) under the influence of biotic controlling factors. One of which are parasites. Parasites will try to include an invader in its PS. However, the impact of the parasite on the introducing species may be indifferent, limiting or depleting. Depending on the properties of the invading species and nature of indigenous parasite.
A typical example is the introduction to the Azov and Black Sea the Far Eastern mullet $M$. soiuy. This mullet was intended solely for cultivation in the lagoons of the Azov Sea, artificially isolated from the natural ecosystem. After some time, one such lagoon dam was destroyed during a storm and the haarder was released. This species quickly settled in the Azov Sea and increased its population quantity and went to the Black Sea, greatly surpassing the local mullet species in their ecological niche. Reaction of indigenous parasites on invader was different (Figure 5). Monogeneans Ligophorus vanbenedenii, defected to it from the local mullet was indifferent to $M$. soiuy. It showed no overt aggression to the stranger [18]. Another parasite myxosporeans Myxobolus parvus infected more than $50 \%$ of the haarder population with obvious signs of gill necrosis, anemia and weakening of the host, but non-fatal. There has been a limiting effect of the parasite, indirectly leading to a reduction of the host population. The third species, microsporidia Glugea stephany, also parasitic on the gills, passed on haarder from native flounder Platichthys flesus and caused epizootic and massive death of invader. According to the Central Azov Ichthyological Groups in one estuary were killed 477 million fry and 14,000 of adults haarder [19].

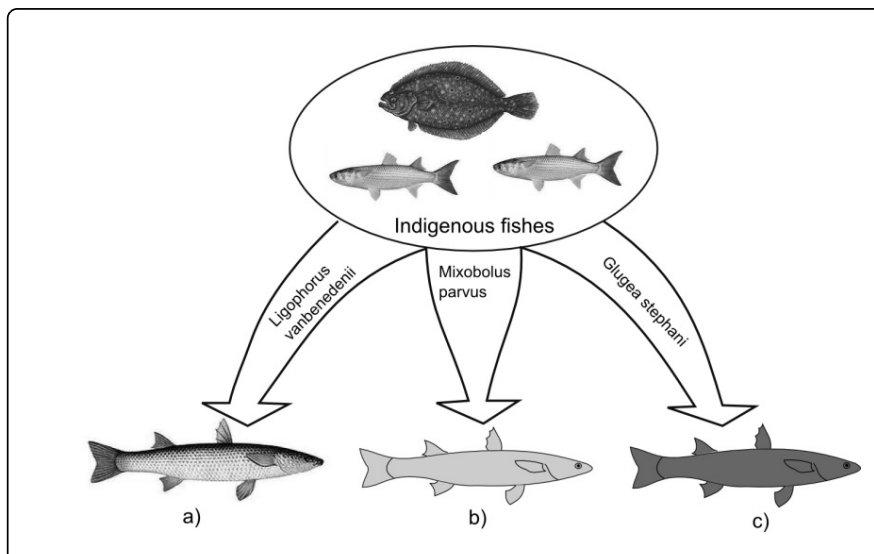

Figure 5: Scheme of interaction of indigenous parasites with fish invader species $M$. soiuy: $\mathrm{a}$ - indifferent effect; $\mathrm{b}$ - limiting effect; $\mathrm{c}$ - depleting effect.

\section{Conclusion}

Parasites, as an important, but aggressive component of all without exception marine ecosystems deserve more attention when considering the challenges of introduced species. Their resettlement is an objective reality and it must be investigated through monitoring plans and establishment of local host-parasite data bases. All introductions to some extent lead to an imbalance or successional ecosystems. In order to avoid provocative succession it is required to understand and to know the mechanisms of introduction. Considered above possible mechanisms of resettlement parasites in marine space are not exhaustive and are in need of further study.

To assess the real situation of invasive parasites need regular studies as parasite fauna and functioning of parasitic systems. New knowledge is not keeping pace with human activity. Therefore it is extremely important to establish strict control of introduced species in the interests of the individual to prevent drifting alien parasite species in other ecosystems and timely forecast attacks on invasive species the local parasites. 
Citation: Volodymyr KM, Al-Jufaili S, Khalfan R, Al-Mazrooei NAM (2015) Marine Parasites as an Object and as a Factor in the Problem of Invasive Species in Marine Ecosystems: Reflections on the Topic. J Biodivers Endanger Species 3: 154. doi: $10.4172 / 2332-2543.10 .4172 / 2332-2543.1000154$

Page 5 of 5

\section{References}

1. Parhizi A (2014) ROPME Sea Area Strategic Action Plan (SAP) and its roadmap towards ballast water management convention implementation. Presented at: Conference on Marine Invasive Species: Management of Ballast Water and Other Vectors, 17-19 February, 2014, Muscat, Sultanate of Oman. Ministry of Environment \& Climate Affairs, Aquatic Ecosystem Health and Management Society.

2. Mackenzie K (1999) Parasites as indicators of environmental change and pollution in marine ecosystems.Qatar Univ Sci J 19: 128-136.

3. Beklemishev VN (1956) Vozbuditely bolezney kak chleny biocenozov. (Pathogens as members of biocenosis. In Russian) Zool Journal 35: 1729-1765.

4. Odum G, Odum E (1978) Energeticheskyi Basis Cheloveka i Prirody. (Energetic basis of Humanity and Nature. In Russian). P.H. Progress Moscow, USSR.

5. Schultz RS, Gvozdev EV (1970) Osnovy obschey helmintologii. (Foundations of General Helminthology. In Russian) V.1, P.H. Nauka, Moscow, USSR.

6. Merella P, Cherchi S, Garippa G, Fioravanti ML, Gustinelli A, et al. (2009) Outbreak of Sciaenacotyle panceri (Monogenea) on cage-reared meagre Argyrosomus regius (Osteichthyes) from the western Mediterranean.Sea Dis Aquat Org 86: 169-173.

7. Villalba A, Mourelle SG, Carballal MJ, Lopez C (1997) Symbionts and diseases of farmed mussels Mytilus galloprovincialis throughout the culture process in in the Rias of Galicia (NW Spain) Dis Aquat Org 31: 127-139.

8. Machkevsky VK (2007) The commensals, parasites and diseases of Black Sea mussel. In: Ivanov V.N. (Eds.) Marikultura midiy na Chernom more. NANU, InBUM.- Sevastopol P. 196-220. P.H. EKOSIGidrophisika,Ukraine.
9. Machkevsky VK (1984) Biology and Ecology of trematode Proctoeces maculatus - parasite of Black Sea mussel. All-Union Institute of Helminthology named after KI Scriabin - Moscow, USSR.

10. Calvo-Ugarteburu G, McQuaid CD (1998) Parasitism and introduced species: epidemiology of pidemiology of trematodes in the intertidal mussels Perna perna and Mytilus galloprovincialis 220: 47-65.

11. Sapota MP (2006) NOBANIS - Invasive Alien Species Fact Sheet Neogobius melanostomus. - From: Online Database of the North European and Baltic Network on Invasive Alien Species - NOBANIS www.nobanis.org

12. Kvach Y, Stepien CA (2008) Metazoan Parasites of Introduced Round and Tubenose Gobies in the Great Lakes: Support for the "Enemy Release Hypothesis". J Great Lakes Res Internat Assoc Great Lakes Res 34: 23-35.

13. Cariton JT, Geller JB (1993) Ecological roulette: the global transport of nonindigenous marine organisms.Science 261: 78-82.

14. Torchin ME, Lafferty KD, Kuris AM (2002) Parasites and marine invasions. Parasitology, Cambridge University Press 124: 137-151.

15. Dmitrieva EV (1996) Fauna of Monogenea of the Far-East Mugil soiuy in the Black Sea.Vestnik Zoologii 4: 95-97.

16. Osmanov SO (1971) Parasites of Fishes of Uzbekistan.Tashkent, USSR: FAN.

17. Zholdasova I (1997) Sturgeons and the Aral Sea ecological catastrophe.Environmental Biology of Fishes 48: 373-380.

18. Pankov P (2011) Helminths and helminth communities in mullets from the Bulgarian Black Sea coast. Ph.D. dissertation, Bulgarian Academy of Sciences, Sofia.

19. Maltsev VN (1997) About mass mortality of haarder in Milk Estuary of Azov Sea. Proceedings of the First Congress of Ichthyologist of Russia. Astrahan, September 1997. P.H. VNIRO, Moscow M., 380. 